\title{
ANALISIS PROFITABILITAS USAHA JAGAL SAPI DI RUMAH POTONG HEWAN KOTA KENDARI
}

\author{
Azwanda ${ }^{1}$, La Ode Arsad Sani ${ }^{2}$ dan Rahim Aka ${ }^{2}$ \\ ${ }^{1}$ Alumni Fakultas Peternakan Universitas Halu Oleo \\ ${ }^{2}$ Dosen Fakultas Peternakan Universitas Halu Oleo \\ Email: aswandafpt13@yahoo.com
}

\begin{abstract}
ABSTRAK
Penelitian ini dilakukan untuk mengkaji besarnya pendapatan dan profitabilitas agribisnis usaha jagal sapi di Rumah Potong Hewan Kota Kendari. Penetapan responden menggunakan metode sensus sebanyak 13 orang pejagal. Data dikumpulkan dengan cara wawancara menggunakan alat bantu kuesioner terhadap responden, yang dilaksanakan bulan Oktober 2016. Data yang terkumpul selanjutnya ditabulasi, dianalisis secara kualitatif dan kuantitatif. Hasil penelitian menunjukan bahwa sapi yang dipotong setiap bulan sebanyak 480/bulan atau 37 ekor/ pejagal yang menghasilkan daging sebanyak $31.600 /$ bulan atau $2.430,8 \mathrm{~kg} /$ pejagal. Rata-rata pendapatan pejagal setiap bulan adalah Rp.36.552.840 dengan nilai profitabilitas yaitu $17,73 \%$ yang menunjukan mempunyai prospek yang baik dengan perolehan nilai profitabilitas lebih tinggi dibanding tingkat suku bunga bank yang berlaku.
\end{abstract}

Kata kunci: Profitabilitas, Pendapatan, Usaha jagal, Ternak sapi, dan RPH

\begin{abstract}
This study was conducted to examine the amount of income and agribusiness profitability of slaughterhouse business at slaughterhouse of Kendari City. Determination of respondent is held by using census method as much as 13 slaughterers. Data was collected with interview by using questionnaires to respondent, held on October 2016. Collected data then tabulated and analyzed qualitatively and quantitatively. Result of the research showed that cattle was slaughtered as many as 480 cattle per month or 37 cattle per slaughterer, producing meat as much as $31.600 \mathrm{~kg}$ per month or $2.430 .8 \mathrm{~kg}$ per slaughterer with profitability value $17.73 \%$ that showed good prospect indicated from higher profitability value compared with the prevailing bank interest rate.
\end{abstract}

Key words: Profitability, income, slaughtering business, cattle, slaughterhouse. 


\section{PENDAHULUAN}

Sub sektor peternakan merupakan bagian dari sektor pertanian yang memiliki peranan cukup penting dalam memberikan kontribusi yang cukup besar terhadap perekonomian nasional. Salah satu kegiatan di bidang sub sektor peternakan yang memberikan kontribusi terhadap perekonomian masyarakat adalah usaha jagal. Usaha jagal merupakan kegiatan agribisnis peternakan yang berfungsi sebagai sub sistem pemasaran hasil ternak. Rangkaian kegiatan usaha jagal ternak sapi dimulai dari pembelian sapi hidup, proses pemotongan yang menghasilkan produk berupa daging segar/karkas dan hasil ikutannya. Secara tradisional seorang jagal harus mempunyai pengalaman dalam menaksir bobot hidup sapi dan menaksir harga sapi yang akan dibeli. Kriteria penaksiran harga pada umumnya berdasarkan umur, bobot badan serta karkas setelah sapi dipotong (Abidin, 2002). Oleh karena itu seorang pejagal sapi memerlukan modal yang relatif besar dalam menjalankan usahanya, terutama untuk membeli bahan baku berupa sapi potong. Semakin besar biaya yang dialokasikan dalam usaha jagal maka jumlah produksi semakin meningkat sehingga jumlah pendapatan yang diharapkan juga semakin meningkat. Berdasarkan data RPH Kota Kendari pada tahun 2016 bahwa jumlah pejagal ternak sapi hingga saat ini yang terdaftar dan menjalankan aktifitas usaha jagal sebanyak 25 orang. Namun fakta menunjukkan tidak semua pejagal tersebut menjalankan usaha pemotongan sapi secara rutin setiap harinya. Jumlah pejagal sapi yang rutin menjalankan usahanya di RPH berkisar antara 10-15 orang saja setiap bulannya, karena keterbatasan modal usaha (Penelitian pendahuluan, 2016).

Profitabilitas merupakan ukuran relatif terhadap persentase laba bersih yang diperoleh dari sejumlah modal yang di investasikan. Pendapatan pejagal sapi ditentukan oleh besarnya nilai penerimaan dalam setiap proses produksi. Variabel harga pembelian sapi hidup akan mempengruhi harga jual daging sapi. Semakin tinggi biaya pembelian ternak sapi maka harga penjualan daging sapi juga akan relatif meningkat. Harga sapi relatif tetap normal dan bahkan dapat dibeli oleh pejagal dengan harga relatif murah sehingga dijual pada konsumen dengan harga relatif terjangkau. Berdasarkan uraian pada latar belakang, maka perlu dilakukan penelitian Analisis Profitabilitas Usaha Jagal Sapi di Rumah Potong Hewan Kota Kendari.

\section{MATERI DAN METODE}

Penelitian ini dilaksanakan di Rumah Pemotongan Hewan (RPH) Kota Kendari pada bulan oktober 2016. Populasi dalam penelitian ini adalah seluruh pejagal sapi yang ada di Rumah Potong Hewan Kota Kendari sebanyak 13 orang. Sampel penelitian adalah pejagal yang beraktifitas secara rutin melakukan pemotongan sapi di Rumah Potong Hewan Kota Kendari setiap hari. Metode pengambilan sampel/responden dalam penelitian ini dilakukan dengan metode sensus sehingga hasil penelitian ini dapat menggambarkan secara utuh dan menyeluruh mengenai perilaku pejagal sapi terhadap risiko usaha. Hal ini sesuai pendapat Rianse dan Abdi (2008) bahwa sensus merupakan penelitian yang dapat mengungkapkan ciri-ciri populasi (parameter) secara akurat dan komprehensif. Pengumpulan data 
dilakukan dengan metode wawancara melalui seperangkat questioner yang telah dipersiapkan, meliputi karakteristik responden, identitas usaha jagal sapi, modal yang ditanam, komponen input, komponen output. Variabel yang diamati dalam penelitian ini adalah: Karakteristik responden (pejagal sapi) meliputi: umur, tingkat pendidikan, pengalaman, dan pelatihan. Usaha jagal sapi yang meliputi: Biaya tetap seperti : Biaya penyusutan, kendaraan, freezer, parang/pisau, kampak, timbangan, batu asah, tali, listrik dan air. Biaya variabel meliputi :Pembelian sapi, transportasi, retribusi, tenaga kerja, sewa penampungan dan kemasan/karung; Jumlah ternak yang dipotong. Penerimaan dari penjualan daging sapi. Adapun teknik Analisis yang digunakan dalam penelitian ini yaitu karateristik usaha jagal sapi akan dijelaskan secara deskriptif, Besarnya total penerimaan (TR) usaha jagal adalah perkalian antara produksi yang diperoleh dengan harga jual. Dengan rumus matematis

$$
\mathbf{T R}=\mathbf{Y} . \mathbf{P}
$$

Dimana:

$\mathrm{TR}=$ Total penerimaan usaha jagal sapi

$\mathrm{Y}=$ Produksi dalam usaha jagal sapi

$P=$ Harga jual daging $\&$ hasil ikutannya

Besarnya pendapatan pejagal sapi diketahui dengan menggunakan analisis pendapatan usaha jagal sapi dengan mengurangi total penerimaan dengan total biaya produksi selama proses produksi (Budiraharjo dkk., 2011) dengan rumus

Dimana:

$$
\pi=\mathbf{T R}-\mathbf{T C}
$$

$\pi=$ Keuntungan/pendapatan usaha jagal

$\mathrm{TR}=$ Total penerimaan usaha jagal

$\mathrm{TC}=$ Total biaya usaha jagal
Profitabilitas pejagal akan ditabulasi dan dianalisis menggunakan rumus menurut pendapat (Budiraharjo dkk., 2011)

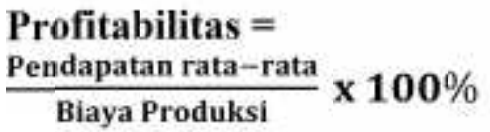

Kriteria Profitabilitas:

- Jika nilai profitabilitas < tingkat suku bunga bank, maka usaha tersebut tidak layak dilakukan karena tidak mampu menghasilkan keuntungan.

- Jika nilai profitabilitas > tingkat suku bunga bank, maka usaha tersebut layak dilakukan karena mampu menghasilkan keuntungan.

\section{HASIL DAN PEMBAHASAN}

\section{Karateristik Responden Usaha Jagal Sapi}

Jagal sapi yang berumur produktif (15-55 tahun) berjumlah 10 orang (76,92\%; sedangkan sisanya sudah berusia lanjut. Seseorang yang memiliki umur lebih muda cenderung akan memiliki kemampuan fisik yang lebih kuat dari pada mereka yang sudah berumur tua. Hal ini didukung oleh pernyataan Fatati (2001) bahwa semakin mudah umur seseorang maka semakin muda menerima perubahan dari luar karena selalu mencoba sesuatu yang baru sebagai upaya untuk meningkatkan pengetahuan dan keterampilan dalam diversifikasi usahanya. Tingkat pendidikan jagal sapi di RPH Kota Kendari, umumnya sudah relatif baik yaitu SD- SLTP berjumlah 4 orang (30\%), SLTA- Sarjana berjumlah 9 orang $(70 \%)$. Hal ini sejalan dengan pendapat 
Gould dan Saupe (1989) bahwa umur, pendidikan dan pelatihan sebagai variabel yang mempengaruhi produktivitas tenaga kerja dalam off-farm, pekerjaan usaha tani dan rumah tangga; 8 orang $(61,53 \%)$ pejagal sapi menjadikan usaha jagal sapi sebagai pekerjaan utama karena para pejagal memperoleh penghasilan 70$100 \%$ untuk memenuhi kebutuhan rumah tangganya dan 5 orang $(38,46 \%)$ menjadikan usaha jagal sebagai usaha sambilan. Usaha utama sebagai pejagal yaitu untuk memperoleh pendapatan keluarga dan sebagai tabungan dimasa depan. Sejalan dengan pernyataan Sumbayak (2006) yang mengelompokkan jenis usaha sebagai usaha pokok dengan pendepatan dari ternak 70-100\%.

Dalam usahanya, pengalaman usaha jagal sapi antara 1-4 tahun sebanyak 2 orang (15\%), lama usaha 5-10 tahun berjumlah 5 orang (39\%) sedangkan lebih dari 10 tahun sebanyak 6 orang (46\%). Hal ini menunjukan bahwa para pejagal di lokasi penelitian dominan memiliki pengalaman usaha lebih dari 10 tahun. Pernyataan ini sejalan dengan pemikiran Febriana dan Mairika (2008), bahwa lama usaha dan pengalaman dalam berusaha akan memberikan indikasi bahwa pengetahuan dan keterampilan peternak terhadap manajemen pemeliharaan ternak mempunyai kemampuan yang lebih baik, lama beternak sangat berpengaruh terhadap keberhasilan usaha; Tanggungan keluarga pejagal sapi di RPH Kota Kendari berkisar 2-3 orang 31\%, dan 4-5 orang berjumlah 9 orang $69 \%$. Jumlah tanggungan merupakan salah satu penunjang keputusan dan penyediaan tenaga kerja dalam usaha jagal sapi agar bisa memenuhi kebutuhan keluarganya sehari-hari namun pejagal tidak mengambil tenaga kerja keluarga dalam menjalankan usahannya karena keluarga pejagal seperti anak masih menempuh pendidikan.

\section{Karakteristik Usaha Jagal Sapi}

Sumber modal usaha jagal sapi, di lokasi penelitian sebagian besar $(85 \%)$ menggunakan modal sendiri untuk memulai usahannya dan hanya $15 \%$ pejagal yang menggunakan modal pinjaman. Kondisi ini menunjukkan bahwa sebenarnya pejagal mempunyai kemampuan yang memadai secara ekonomi karena bisa mendanai sendiri usahanya sebagai modal. Modal sendiri adalah modal yang diperoleh dari pemilik usaha itu sendiri. ( Mardiyatmo. 2008). Dalam ushanya tenaga kerja yang terlibat dalam usaha jagal di lokasi penelitian umumnya tenaga kerja lepas yaitu berjumlah 49 orang dengan upah kerja antara Rp.100.000- Rp.110.000,00/ekor sebagai pemotong sapi. Pejagal sapi di lokasi penelitian cenderung tidak menggunakan tenaga kerja keluarga; Pejagal sapi tidak melakukan pembelian ternak sapi setiap harinya, hal ini untuk menghindari besarnya biaya yang dikeluarkan dan kurangnya permintaan daging. Pembelian sapi yang terbanyak adalah yang dilakukan tiap minggu sekali yaitu sebanyak 8 orang $61 \%$, sedangkan tidak menentu yaitu sebanyak 5 orang $39 \%$. Kondisi ini dapat dikategorikan bahwa pembelian ternak sapi dapat disesuaikan dengan permintaan pasar dan kondisi keuangan yang menjalankan usaha.

Pengelolaan pemotongan ternak di
RPH mulai dari perlakuan ternak
sebelum dipotong, pemotongan dan
perlakuan setelah dipotong (postmortem).
Perlakuan ternak sebelum dipotong
seperti pemeriksaan antemortem


dilakukan pada saat ternak diistirahatkan. Proses pemotongan mulai dari penyembelihan, pengulitan, pemisahan bagian-bagian daging dan penimbangan daging. Proses penyembelihan dilakukan dengan cara diikat ditiang langsung disembelih kemudian proses pengulitan dilakukan di lantai, digantung namun tidak menggunakan mesin, lalu pemisahan bagian-bagian daging yang langsung dilakukan pengkarkasan dan terakhir proses penimbangan dengan berat daging antara 40-80 $\mathrm{Kg} / \mathrm{ekor}$. Ternak yang dipotong dominan berjenis kelamin jantan. Menurut pejagal merasa cukup nyaman dan terfasilitasi dengan melakukan pemotongan di RPH Kota Kendari. Hal ini sesuai dengan pendapat bahwa beberapa persyaratan untuk memperoleh hasil pemotongan ternak yang baik yaitu: (1) ternak harus tidak diperlakukan secara kasar, (2) ternak tidak mengalami stres, (3) penyembelihan dan pengeluaran darah harus secepat dan sesempurna mungkin, (4) kerusakan karkas harus minimal, (5) cara pemotongan harus higienis, (6) ekonimis dan (7) aman bagi para pekerja abatoar. (Swatland, 1984).

Ternak sapi berasal dari beberapa daerah yang terdapat di Sulawesi Tenggara. Ada yang dari Kabupaten Muna, Bombana, Kolaka Timur, Kolaka Utara, Kolaka, Konawe Utara, Konawe, Konawe Selatan dan Kota Kendari. Daerah yang sering dan hampir tiap hari dikunjungi oleh pejagal sapi selama penelitian adalah daerah Konawe Selatan. Kondisi ini diakibatkan karena Konawe Selatan adalah daerah yang memiliki populasi ternak sapi terbanyak dan akses ke daerah Konawe Selatan sangat dekat. Umumnya ternak sapi yang dipotong oleh pejagal adalah sapi bali karena yang paling banyak dipelihara oleh masyarakat peternak khususnya daerah Sulawesi Tenggara adalah sapi bali. Daerah yang kurang dikunjungi oleh pejagal sapi adalah daerah Muna. Kondisi ini diakibatkan karena daerah ini memiliki jarak yang sangat jauh dengan tempat pemotongan ternak sapi serta biaya yang dibutuhkan sangat besar jika dibandingkan dengan daerah lain.

\section{Profitabilitas Usaha Jagal Sapi}

Profitabilitas suatu perusahaan dapat dinilai melalui berbagai cara tergantung pada laba dan aktiva atau modal yang akan diperbandingkan satu dengan lainya, (Simamora, 2001). Komponen yang termasuk dalam perhitungan profitabilitas antara lain adalah biaya, penyusutan , penerimaan dan pendapatan.

\section{Biaya Produksi}

Biaya produksi adalah sejumlah uang yang dikeluarkan oleh pejagal untuk melaksanakan kegiatan usaha yang dijalankan. (Soekartawi, 2002). Biaya produksi dapat didefenisikan sebagai jumlah biaya yang dikeluarkan untuk keperluan perusahaan, biaya ini dikelompokkan menjadi dua yaitu biaya tetap dan biaya tidak tetap. Struktur biaya produksi yang dikeluarkan peternakan dalam usaha jagal sapi dapat dilihat pada Tabel 1 . 
Tabel 1. Rata-rata Biaya Produksi Usaha Jagal Sapi di RPH Kota Kendari Selama Satu Periode (1 bulan)

\begin{tabular}{|c|c|c|c|c|c|c|}
\hline No & Uraian & Volume & Satuan & $\begin{array}{c}\text { Harga } \\
\text { Satuan } \\
(\mathbf{R p})\end{array}$ & $\begin{array}{c}\text { Jumlah } \\
\text { Biaya } \\
\text { (Rp/bulan) }\end{array}$ & $\begin{array}{l}\text { Rata-Rata Biaya } \\
\text { (Rp/orang/bulan) }\end{array}$ \\
\hline \multirow{3}{*}{1.} & Biaya Tetap & & & & & \\
\hline & Retribusi & 52 & Kali & 196.153 & 10.200 .000 & 784.615 \\
\hline & Pengangkutan & & angkut & & & \\
\hline 2. & Retribusi RPH & 480 & Ekor & 50.000 & 24.000 .000 & 1.846 .153 \\
\hline 3. & $\begin{array}{l}\text { Upah Tenaga } \\
\text { Kerja (49 orang) }\end{array}$ & 480 & $\begin{array}{l}\text { Ekor } \\
\text { sapi }\end{array}$ & 102.375 & 49.140 .000 & 3.780 .000 \\
\hline 4. & $\begin{array}{l}\text { Sewa } \\
\text { Penampungan }\end{array}$ & 480 & $\begin{array}{l}\text { Ekor } \\
\text { sapi }\end{array}$ & 20.000 & 9.600 .000 & 738.461 \\
\hline 5. & $\begin{array}{l}\text { Penyusutan } \\
\text { Peralatan } \\
\text { Biaya Variabel }\end{array}$ & - & - & & 9.759 .583 & 750.737 \\
\hline 1. & Pembelian Sapi & 480 & Ekor & 5.324 .308 & 2.556 .500 .000 & 196.653 .846 \\
\hline 2. & Transportasi & 52 & $\begin{array}{l}\text { Kali } \\
\text { Angkut }\end{array}$ & 322.115 & 16.750 .000 & 1.288 .461 \\
\hline 3. & Karung & 1.868 & Unit & 2.000 & 3.736 .000 & 287.384 \\
\hline \multirow[t]{2}{*}{4.} & Listrik & 13 & Pejagal & 37.500 & 487.500 & 37.500 \\
\hline & Jumlah & & & & 2.680 .173 .083 & 206.167.160 \\
\hline
\end{tabular}

Sumber: Data Primer Setelah Diolah, 2017

Hasil penelitian menunjukkan bahwa biaya produksi dikeluarkan dalam usaha jagal sapi di RPH Anggoeya Kota Kendari sebesar Rp 2.680.173.083/ periode (1 bulan) dalam waktu satu periode dengan rata-rata Rp 206.167.160. Biaya yang paling besar digunakan dalam usaha ini adalah pembelian sapi dengan biaya sebesar Rp 2.556.500.000. Besarnya biaya yang dikeluarkan dalam pembelian ternak sapi disebabkan karena ternak sapi merupakan input utama dalam usaha khususnya ternak sapi potong. Ternak sapi potong merupakan salah satu sumberdaya bahan makanan berupa daging yang memiliki nilai ekonomis tinggi dan penting artinya dalam kehidupan masyarakat. Ternak sapi potong bisa menghasilkan berbagai macam kebutuhan terutama daging disamping hasil ikutan lain seperti kulit, jeroan, pupuk dan tulang. (Sugeng, 2000).

\section{Penerimaan Usaha Jagal Sapi}

penerimaan merupakan jumlah uang yang diperoleh dari penjualan sejumlah output atau dengan kata lain sebagai pendapatan yang diperoleh oleh perusahaan hasil dari penjualan hasil produksinya. (Ferryanto, 2011). Penerimaan dari usaha jagal sapi meliputi hasil penjualan dari daging, tulang, kulit, kepala, kaki dan jeroan. Adapun penerimaan dari hasil penjualan usaha jagal sapi dapat dilihat pada Tabel 2 . 
Tabel 2. Penerimaan Rata-Rata Pejagal Sapi di RPH Kota Kendari Selama 1 Periode (1 Bulan)

\begin{tabular}{lrrrr}
\hline Komponen Penerimaan & Volume & $\begin{array}{c}\text { Harga Satuan } \\
(\mathbf{R p} / \mathbf{k g})\end{array}$ & \multicolumn{1}{c}{$\begin{array}{c}\text { Jumlah } \\
(\mathbf{R p} / \mathbf{b u l a n})\end{array}$} & $\begin{array}{c}\text { Rata-Rata } \\
\text { (Rp/bulan/orang) }\end{array}$ \\
\hline Daging (Kg) & 31.600 & 80.000 & 2.528 .000 .000 & 194.461 .538 \\
Tulang (Kg) & 8.160 & 35.000 & 285.600 .000 & 21.969 .230 \\
Kulit (Kg) & 7.680 & 7.000 & 53.760 .000 & 4.135 .384 \\
Kepala/kaki (Pasang) & 480 & 150.000 & 72.000 .000 & 5.538 .461 \\
Jeroan (Kg) & 7.200 & 30.000 & 216.000 .000 & 16.615 .384 \\
\hline Jumlah & & & $\mathbf{3 . 1 5 5 . 3 6 0 . 0 0 0}$ & $\mathbf{2 4 2 . 7 2 0 . 0 0 0}$ \\
\hline
\end{tabular}

Sumber: Data Primer Setelah Diolah, 2017

Hasil penelitian menunjukkan bahwa penerimaan usaha jagal sapi RPH Anggoeya Kota Kendari selama satu periode (1 bulan) sebesar Rp. 3.155.360.000 dengan rata-rata $\mathrm{Rp}$. 242.720.000/ bulan/ orang. Jumlah ini diperoleh dari hasil penjualan daging, tulang, kulit, kepala/kaki dan jeroan. Berdasarkan hasil penelitian menunjukkan bahwa penerimaan yang tertinggi adalah berasal dari hasil penjualan daging $\mathrm{Rp}$ 2.528.000.000 dari $31.600 \mathrm{~kg}$ per periode dengan rata-rata penerimaan Rp 194.461.538. Satu kilo daging dijual dengan harga Rp. 80.000. Jenis produksi yang terendah terdapat hasil penjualan kulit dengan jumlah Rp 53.760.000 dengan rata-rata $\mathrm{Rp}$. 4.135.384 dari $7.680 \mathrm{~kg}$. Satu kilo kulit dijual dengan harga RP. 7.000. Kondisi ini disebabkan karena daging merupakan salah satu kebutuhan yang mendasar serta memiliki nilai jual yang tinggi jika dibandingkan dengan kepala dan kaki. Disamping itu, daging memiliki skala permintaan dan tingkat konsumsi yang lebih tinggi dibandingkan dengan hasil produksi yang lain. Pernyataan ini sejalan dengan pemahaman Anonimous, (2012) bahwa salah satu faktor yang mempengaruhi terbentuknya harga daging sapi adalah tingkat konsumsi masyarakat.

\section{Pendapatan dan Profitabilitas Usaha Jagal Sapi}

Keuntungan merupakan penghasilan yang timbul akibat adanya aktivitas dalam sebuah usaha yang biasa dikenal dengan sebutan yang berbeda seperti penjualan, penjualan jasa (fees), bunga, dividen, royalti, dan sewa. Pendapatan merupakan hal yang sangat penting, karena pendapatan dapat menjadi objek atas kegiatan dalam sebuah kegiatan usaha. Keuntungan dalam usaha jagal sapi dapat dilihat pada Tabel 3.

Tabel 3. Rata-Rata Pendapatan Usaha Jagal Sapi Selama 1 Periode (1 Bulan)

\begin{tabular}{lcc} 
Uraian & $\begin{array}{c}\text { Jumlah } \\
\text { Pendapatan/Bulan }(\mathbf{R p})\end{array}$ & $\begin{array}{c}\text { Rata-rata Pendapatan/ } \\
\text { Bulan/Orang (Rp) }\end{array}$ \\
\hline Total Penerimaan & 3.155 .720 .000 & 242.720 .000 \\
Total Biaya & 2.680 .173 .083 & 206.167 .160 \\
Total Pendapatan & $\mathbf{4 7 5 . 1 8 6 . 9 1 7}$ & $\mathbf{3 6 . 5 5 2 . 8 3 9}$ \\
\hline
\end{tabular}

Sumber: Data Primer Setelah Diolah 
Hasil penelitian menunjukkan bahwa pendapatan hasil usaha jagal sapi adalah Rp.475.186.917 jumlah ini diperoleh dari total penerimaan Rp.3.155.720.000 dikurangi dengan total biaya Rp.2.680.173.083, dengan pendapatan perperiode/orang sebesar Rp.36.552.839. Besarnya pendapatan yang dihasilkan dapat menggambarkan potensi usaha jagal sapi agar dapat dikembangkan. Hasil ini seiring pendapat Sudarmono dan Sugeng (2009) bahwa usaha ternak sapi potong merupakan salah satu usaha yang sangat potensial untuk dikembangkan. Angka profitabilitas $17,73 \%$ tersebut dapat dikatakan agribisnis jagal sapi di RPH Anggoeya Kota Kendari cukup baik karena nilai profitabilitas lebih besar dari suku bunga Bank Sultra yang berlaku saat ini $(11,5 \%$. Apabila nilai profitabilitas lebih besar dari suku bunga Bank yang berlaku, maka usaha tersebut layak untuk dikembangkan karena dapat menghasilkan keuntungan. (Riyanto, 2001),

\section{KESIMPULAN}

Berdasarkan hasil penelitian dapat diambil disimpulkan bahwa pendapatan usaha jagal sapi di RPH Anggoeya Kota Kendari dalam satu periode adalah Rp.36.552.839/ bulan/ orang dan profitabilitas diperoleh sebesar $17,73 \%$.

\section{DAFTAR PUSTAKA}

Abidin, Z. 2002. Penggemukan Sapi Potong. PT. Agro Media Pustaka. Jakarta.

Anonimous. 2012. Konsep Sikap Konsumen.(elearning.upnjatim.ac.i d/) diakses pada 28-12-2012.
Budiraharjo, K., M. Handayani., dan G. Sanyoto, 2011. Analisis profitabilitas usaha penggemukan sapi potong di Kecamatan Gunung Pati Kota Semarang. Jurnal Ilmuilmu pertanian MEDIAGRO Vol 7, (1): 1-9.

Fatati. 2001. Perilaku petani peternak dalam diversifikasi tanaman kelapa sawit dengan ternak sapi potong di daerah transmigrasi sungai Bahar Kabupaten Muaro. Jurnal Ilmu-Ilmu Peternakan. Vol 4. (2) : 92-98.

Febriana. D dan Mairika. 2008. Pemanfaatan limbah pertanian sebagai pakan ruminansia pada peternakan rakyat di Kecamatan Renggat Barat Kabupaten Indragiri Hulu. Jurnal Peternakan. Vol 5. (1) : 23-37.

Ferryanto, 2011. Pengertian-PenerimaanJenis-Jenis http://ferryantooo.blogspot.com/201 1/02/pengertian-penerimaan-jenisjenis.html. Di akses pada tanggal 10 Januari 2013.

Gould, B. W. and W.E. Saupe. 1989. Offfarm labor market entry and exit. Am. J. Agric. Econ. 71(4): 960 969.

Mardiyatmo. 2008. Kewirausahaan.

Yudisthira. Jakarta.

Riyanto, B. 2001. Dasar-Dasar Pembelanjaan Perusahaan. Edisi ke4 BPFE. Universitas Gadjah Mada, Yogyakarta.

Rianse, U.dan Abdi. 2008. Metodelogi Penelitian Sosial dan Ekonomi Teori dan Aplikasi. Alfabeta. Bandung.

Simamora, B. 2001. Memenangkan Pasar dengan Pemasaran Efektif dan Profitabel. Edisi pertama. Jakarta: PT. Gramedia Pustaka Utama. 
Soekartawi. 2002. Prinsip Dasar Ekonomi Pertanian. Penerbit PT Raja Grafindo Persada, Jakarta.

Sudarmono dan Sugeng. 2009. Sapi Potong (edisi revisi). Penebar Swadaya. Jakarta.

Sumadi, 2003. Penelitian Mutu Genetik Sapi Ongole dan Brahman. Universitas Gadjah Mada Press Yogyakarta.

Sumbayak. J. B. 2006. Materi, Metode dan Media Penyuluhan. Fakultas Pertanian. Universitas Sumatera Utara. Medan.

Sugeng, Y. B., 2000. Sapi Potong. Penebar Swadaya, Jakarta.

Swatland, H.J. 1984. Structure and Development of Meat Animals. Prentice Hall Inc. Englewood Cliffs, New Jersey. 